TITLE:

\title{
Factors affecting photoreactivation in UVB-irradiated herbivorous spider mite (Tetranychus urticae).
}

$\operatorname{AUTHOR}(S)$ :

Murata, Yasumasa; Osakabe, Masahiro

\section{CITATION:}

Murata, Yasumasa ...[et al]. Factors affecting photoreactivation in UVB-irradiated herbivorous spider mite (Tetranychus urticae).. Experimental \& applied acarology 2014, 63(2): 253-265

ISSUE DATE:

2014-06

URL:

http://hdl.handle.net/2433/199611

\section{RIGHT:}

The final publication is available at Springer via http://dx.doi.org/10.1007/s10493-0149773-3.; This is not the published version. Please cite only the published version.; この論 文は出版社版でありません。引用の際には出版社版をご確認ご利用ください。 
1 Factors affecting photoreactivation in UVB-irradiated herbivorous spider mite

2 (Tetranychus urticae)

3

4

5 Yasumasa Murata* and Masahiro Osakabe

6

7 Laboratory of Ecological Information, Graduate School of Agriculture, Kyoto

8 University, Kyoto 606-8502, Japan

9

10

11

12

13 * Correspondence: E-mail murata.yasumasa.22e@st.kyoto-u.ac.jp (Yasumasa Murata)

14

15 Short title: Photoreactivation in spider mite

16

17

18 


\section{ABSTRACT}

Ambient ultraviolet-B (UVB) radiation causes lethal damage to spider mites, and the extent of photochemical effects is determined by cumulative irradiance in the two-spotted spider mite, Tetranychus urticae. However, the $\mathrm{LD}_{50}$ values obtained using a UVB lamp were much lower than those elicited by solar UVB radiation. As solar radiation includes intense visible light and UVA, we assumed that a photoreactivation mechanism would play a role to survive under solar radiation. We assessed the capacity for photoreactivation in T. urticae eggs and larvae, and found that the efficacy of photoreactivation was determined by the cumulative irradiance of visible light (VIS) after exposure to UVB radiation. The wavelength range effective for photoreactivation went from UVA to green. Next, we found that an increased time lag between UVB and VIS radiation reduced the photoreactivation efficacy in eggs. In contrast, a time lag $\leq 4$ $\mathrm{h}$ did not affect that in larvae. We discussed the possibility that the timing photoreactivation occurs related with phase-specific UVB vulnerability and outbreak symptom due to UVB-induced DNA damage. Our results suggest that $T$. urticae depends on a photoreactivation mechanism, and that the photoreactivation efficiency probably caused the divergence in UVB impact between UV lamp and solar radiation.

Keywards: photoenzymatic repair, UV damage, DNA lesion, environmental stress, 


\section{INTRODUCTION}

Ambient ultraviolet-B (UVB; 280-315 nm wavelengths) radiation causes lethal damage to herbivorous spider mites and drives many mites to reside on the lower leaf surfaces of host plants (Ohtsuka and Osakabe 2009; Suzuki et al. 2009; Sakai and Osakabe 2010). The Bunsen-Roscoe reciprocity law (i.e., the extent of photochemical effects is determined by cumulative irradiance) is obeyed in the survival of two-spotted spider mites, Tetranychus urticae Koch (Acari: Tetranychidae), exposed to UVB radiation (Murata and Osakabe 2013). However, the $\mathrm{LD}_{50}$ value for eggs exposed to artificial UVB (laboratory, $0.58 \mathrm{~kJ} \mathrm{~m}^{-2}$; Murata and Osakabe 2013) is lower than that elicited by solar UVB radiation ( $\sim 50 \mathrm{~kJ} \mathrm{~m}^{-2}$; Sakai et al. 2012).

UVB radiation causes DNA damage in organisms, including the formation of pyrimidine dimers such as cyclobutane pyrimidine dimers (CPD) and pyrimidine (6-4) pyrimidone photoproducts. To avoid the harmful effects of UV-induced DNA damage, organisms have two major DNA repair mechanisms: excision repair (dark repair pathways: base excision repair and nucleotide excision repair) and photo-enzymatic repair (PER; Malloy et al. 1997). Excision repair is a multiple enzyme system that replaces the damaged DNA with new, undamaged nucleotides using energy derived from ATP (Sinha and Häder 2002). In PER, DNA lesions are directly repaired by a photolyase using energy from blue visible light (400-450 nm wavelength; Sancar 2003) and ultraviolet-A (UVA; 315-400 nm wavelength; Kalthoff 1975; Shiroya et al. 1984; Sinha and Häder 2002).

As solar radiation includes intense visible light, we assumed that a photoreactivation mechanism would play a role in the survival of T. urticae under solar radiation, causing a difference between laboratory and outdoor experiments. Santos (2005) reported photoreactivation in adult females (survival recovery) of T. urticae and the mold mite, Tyrophagus putrescentiae (Schrank), caused by irradiation by flood lamp after exposure to UVB radiation. Four CPD photolyase genes have been found in the $T$. urticae genome (Grbić et al. 2011). However, the function of photoreactivation is largely unknown in plant-dwelling mites.

We evaluated the factors affecting photoreactivation in T. urticae. First, we assessed the photoreactivation capacity of this mite by testing whether visible light irradiation by 
halogen lamp (VIS) increased T. urticae survivorship after exposure to UVB radiation. Simultaneously, the effects of the intensity and cumulative irradiance of VIS on the photoreactivation efficiency were evaluated. Next, the effects of the time lag between UVB and VIS irradiation and a wavelength of light (including VIS and UVA) on photoreactivation were tested.

\section{MATERIALS AND METHODS}

Mites.

Tetranychus urticae is a ubiquitous polyphagous spider mite and thus an economically important agricultural pest worldwide. The mite population used in this study, which was established from several localities in Japan, was reared on potted kidney bean plants in a laboratory at $25-28^{\circ} \mathrm{C}$.

UVB and halogen lamps.

A UVB lamp (6 W; Panasonic Electric Works Co. Ltd., Osaka, Japan) and two halogen lamps (130 W; JDR110V-85WHM/K7-H; Ushio Lighting Co. Ltd., Tokyo, Japan; set at an interval of $22.5 \mathrm{~cm}$ ) were affixed from a shelf $67 \mathrm{~cm}$ overhead in a dark growth chamber at $25^{\circ} \mathrm{C}$. The irradiance values of the UVB lamp and halogen lamps (VIS) on the shelf were 0.16 and $67.7 \mathrm{~W} \mathrm{~m}^{-2}$, respectively. The UVB radiation peaked at $310 \mathrm{~nm}$ (Fig. 1a). The halogen lamp radiation included a small UVA fraction (Fig. 1b). In all experiments, eggs or larvae were exposed to UVB radiation at $0.16 \mathrm{~W} \mathrm{~m}^{-2}$ for 30 $\min \left(0.288 \mathrm{~kJ} \mathrm{~m}^{-2}\right)$ prior to being exposed to VIS radiation.

The UVB irradiance was measured using an irradiance meter $\left(\mathrm{X} 1_{1}\right)$ equipped with a UV-3702-4 detector head (Gigahertz-Optik GmbH, Türkenfeld, Germany). The VIS irradiance was measured using a photo-radiometer (HD2102.2) equipped with an irradiance measurement probe (LP 471 RAD; Delta OHM, Padova, Italy). The wavelength spectra (indexed by relative intensity [counts]) were measured for each experimental setup using a spectrometer (UFV-VIS F; Spectra Co-op Co., Tokyo, 
Japan).

Dose-response in egg photoreactivation.

Four kidney bean leaf squares $(2 \times 2 \mathrm{~cm})$ were placed on water-soaked cotton in each of two Petri dishes ( $9 \mathrm{~cm}$ in diameter). Five adult $T$. urticae females were introduced onto each leaf disk. The females were allowed to oviposit for $24 \mathrm{~h}$ in a laboratory at $25^{\circ} \mathrm{C}$ under a 16-h light: 8-h dark (16L:8D) photoperiod. Then, the females were removed and the eggs laid on the leaf disks were counted. These Petri dishes were placed on a shelf in a darkened growth chamber and immediately exposed to UVB radiation. A Petri dish assigned to be the dark control (without photoreactivation) was placed inside a cardboard box (dark box: $24.0 \times 16.5 \times 10.8 \mathrm{~cm}$ ) immediately after UVB irradiation.

The dark box with the dark control inside and the other Petri dish (photoreactivation treatment) were set on a shelf and exposed to VIS (halogen lamp) using various combinations of intensities and times; $21.6 \mathrm{~W} \mathrm{~m}^{-2}$ for $40,80,120,160$, or $210 \mathrm{~min}$ (the cumulative irradiances were 51.8, 104, 156, 207, and $272 \mathrm{~kJ} \mathrm{~m}^{-2}$, respectively); $36.8 \mathrm{~W} \mathrm{~m}^{-2}$ for 20, 40, 60, 100, or $140 \mathrm{~min}$ (44.2, 88.3, 132, 221, and 309 $\mathrm{kJ} \mathrm{m}^{-2}$, respectively); $67.7 \mathrm{~W} \mathrm{~m}^{-2}$ for 10,20 , 30, or $60 \mathrm{~min}(40.6,81.2,122$, and $244 \mathrm{~kJ}$ $\mathrm{m}^{-2}$, respectively); and $142 \mathrm{~W} \mathrm{~m}^{-2}$ for $8,15,20,25$, or $35 \mathrm{~min}(68.2,128,170,213$, and $298 \mathrm{~kJ} \mathrm{~m}^{-2}$, respectively).

The voltage provided to the halogen lamps was reduced using a variable autotransformer to achieve irradiances $<67.7 \mathrm{~W} \mathrm{~m}^{-2}$ (100 V) (Fig. 1b). An irradiance of $142 \mathrm{~W} \mathrm{~m}^{-2}$ was accomplished by lifting the Petri dishes to $23 \mathrm{~cm}$ above the shelf $[44 \mathrm{~cm}$ from the halogen lamps (100 V)] using a jack.

After treatment, the Petri dishes, including the photoreactivation treatments and dark control, were immediately placed inside a larger cardboard box $(34.5 \times 37.8 \times 13.5$ $\mathrm{cm}$ ) together in the dark until subsequent observation. The cardboard box was placed in the laboratory at $25^{\circ} \mathrm{C}$. Egg hatchability was checked on day 6 after exposure. We preliminarily confirmed that few eggs hatched later than 6 days post-exposure. This series of treatments was replicated twice. A total of 80-371 eggs/Petri dish (replicate) were used in our experiments. 
The photoreactivation efficiency was calculated using formula (1) (Kelner, 1951):

$$
S=\frac{Y-X}{1-X}
$$

where $S, X$, and $Y$ represent the photoreactivation efficiency, egg hatchability of the dark control, and hatchability of eggs exposed to VIS (photoreactivated), respectively, in each replicate. The effects of VIS intensity, time of VIS irradiation, and cumulative VIS irradiance on the photoreactivation efficiency $(S)$ were evaluated by the stepwise model selection method with the generalised linear model (GLM) based on Akaike's information criterion (AIC) using the "stepAIC" module in the "MASS" package of R software ver. 3.0.0 (R Development Core Team, 2013). Next, the function expected between $S$ and the cumulative VIS irradiance (see Results) was fitted using the nonlinear least-squares method, and pseudo standard errors of the estimated parameters were calculated using the "nlm" module in the "stats" package and "sqrt" module in R software, respectively. We calculated 95\% confidence intervals (CIs) for the predicted regression line based on the pseudo standard errors.

The average egg hatchability for the dark control over all replications and its CI were estimated using the "qt" module in R software after an arc sin root transformation.

Influence of a time lag between UVB and VIS irradiation on photoreactivation in eggs.

Tetranychus urticae eggs in five Petri dishes with four kidney bean leaf squares (2 $\times 2 \mathrm{~cm}$ ) were prepared as dose-response experiments, and all dishes were exposed to UVB radiation. Then, one Petri dish was successively exposed (LAG0) to VIS radiation at an intensity of $67.7 \mathrm{~W} \mathrm{~m}^{-2}$ for $90 \mathrm{~min}$ (cumulative irradiance: $366 \mathrm{~kJ} \mathrm{~m}^{-2}$; photoreactivation treatment). Three of the remaining four dishes were also exposed to VIS radiation under the conditions described above, but at 1, 2, or $4 \mathrm{~h}$ after the end of UVB irradiation (LAG1, LAG2, or LAG4; delayed photoreactivation treatment). The last dish was never exposed to VIS radiation (VIS-; dark control). All Petri dishes were kept inside a cardboard dark box after UVB irradiation except when exposed to VIS radiation.

The hatchability of the eggs was checked under a binocular microscope, every day (10 min to observe each Petri dish) until day 6 after exposure. Although the dark 
condition was briefly broken during these observations, we tentatively confirmed that VIS irradiation later than $24 \mathrm{~h}$ did not cause photoreactivation (Fig. S1). Each series of treatments was performed twice. The number of eggs used in our experiments was 172 281 per Petri dish (replicate).

We transformed the hatchability on day 6 for each replicate to an empirical logit $(E L)$ using the following formula to compare the egg hatchability among the delayed photoreactivation treatments and dark control:

$$
E L=\ln \left(\frac{x+0.5}{n-x+0.5}\right)
$$

where $x$ and $n$ represent the number of eggs hatched (individuals survived for the experiment using larvae), and the total number of individuals tested. The ELs were applied to Bartlett's test for homogeneity of variances using the "bartlett.test" module in $\mathrm{R}$ software. Multiple comparisons by Tukey's HSD method were performed using the "TukeyHSD" module following a one-way analysis of variance (ANOVA) with the "aov" module in R software.

Influence of a time lag between UVB and VIS irradiation on photoreactivation in larvae.

Two kidney bean leaf squares $(2 \times 2 \mathrm{~cm})$ were placed on water-soaked cotton in each of seven Petri dishes. Five adult T. urticae females were introduced onto each leaf disk and allowed to oviposit for $24 \mathrm{~h}$ in the laboratory $\left(25^{\circ} \mathrm{C}, 16 \mathrm{~L}: 8 \mathrm{D}\right)$. After the adult females were removed, the Petri dishes were covered with transparent plastic lids to raise the relative humidity on the leaves. This treatment delays hatching under extremely high humidity until the humidity falls (unpublished observation). A similar suspension of development caused by extremely high humidity was reported in $T$. urticae from teleiochrysalises to adults (Ikegami et al., 2000). Four days later (day 0), the lids were opened and most of the eggs hatched within 30 min. Larvae that had emerged before the lids were opened were removed. We counted the number of emerged larvae $2 \mathrm{~h}$ later, and six of the seven Petri dishes were immediately exposed to UVB radiation. The remaining Petri dish was assigned as the dark control without exposure to UVB (UVB- dark control) and was kept in a cardboard dark box while the other Petri dishes were exposed to UVB radiation and subsequent VIS irradiation. 
After UVB irradiation, each Petri dish was subjected to photoreactivation treatment or used as a dark control with exposure to UVB (UVB+ dark control). One Petri dish was exposed to VIS radiation for $90 \mathrm{~min}\left(366 \mathrm{~kJ} \mathrm{~m}^{-2}\right)$ immediately after UVB irradiation (LAG0), and each of the four dishes were irradiated with VIS 1, 2, 3, or $4 \mathrm{~h}$ later (LAG1, LAG2, LAG3, or LAG4). All Petri dishes were kept inside the cardboard dark box after UVB irradiation except when exposed to VIS radiation.

The status of the mites (living/dead, developmental stage) was recorded on the next day (day 1) and day 8. The observations took 10 min per Petri dish. Each series of treatments was performed twice. The number of larvae used for treatment was 43-94 per Petri dish (replicate).

To evaluate the effects of VIS radiation and the time lag from UVB to VIS irradiation on larval development and survival, we transformed the ratio of individuals that had developed into a protochrysalis (the developmental stage following larva; day 1) or survived (developed to adulthood; day 8) in each replicate to an EL using formula (2). The ELs were applied to Bartlett's test for homogeneity of variances, a one-way ANOVA, and a post-hoc test with Tukey's HSD method using the "bartlett.test," “aov,” Effects of wavelength-filtered VIS and UVA on egg photoreactivation.

Two Petri dishes containing four kidney bean leaf squares $(2 \times 2 \mathrm{~cm})$ with $T$. urticae eggs were prepared using the same procedure as in the dose-response experiments described above, and both Petri dishes were exposed to UVB radiation. Next, one Petri dish was placed inside a dark cardboard box, while the other was exposed to wavelength-filtered light or UVA radiation for $30 \mathrm{~min}$. During irradiation, the Petri dishes assigned for exposure to wavelength-filtered light were placed in a cardboard box $(22.5 \times 12.0 \times 5.20 \mathrm{~cm})$ with a top covered with coloured cellophane film (Toyo, Tokyo, Japan) and illuminated with halogen lamps through the film. The cumulative irradiance values of the filtered lights were 85.5, 88.5, 83.3, and $86.3 \mathrm{~kJ} \mathrm{~m}^{-2}$ for blue (irradiance: $47.5 \mathrm{~W} \mathrm{~m}^{-2}$ ), green $\left(49.2 \mathrm{~W} \mathrm{~m}^{-2}\right.$ ), yellow (without jack; $46.3 \mathrm{~W}$ $\mathrm{m}^{-2}$ ), and red (47.9 $\mathrm{W} \mathrm{m}^{-2}$ ) light, respectively (Fig. 1c). For UVA irradiation, a UVA handy lamp (29.1 W m ${ }^{-2}$; UVL-56 Handheld UV Lamp; UVP, Cambridge, UK) was 
used to test the photoreactivation effects caused by UVA irradiation. UVA irradiance was measured using an irradiance meter (X11) equipped with a UV-3701-4 detector head (Gigahertz-Optik GmbH). The cumulative irradiance value of UVA was $52.4 \mathrm{~kJ}$ $\mathrm{m}^{-2}$.

After radiation exposure, all Petri dishes were placed inside a dark cardboard box and checked for egg hatchability using a binocular microscope on day 6. The series of treatments was replicated twice. A total of 188-284 eggs were used per Petri dish (replication).

We transformed the egg hatchability value (ratio) for each replicate to an $E L$ using formula (2) to compare the effects of coloured VIS and UVA irradiation on photoreactivation. The ELs were applied to Bartlett's test for homogeneity of variances, a one-way ANOVA and a post-hoc test with Tukey's HSD method using the "bartlett.test,” "aov," and “TukeyHSD” modules in R software.

\section{RESULTS}

Dose-response in egg photoreactivation.

The average egg hatchability over all replications for the dark control was 0.106 (95\% CI, 0.096-0.116). The stepwise model selection supported a model including only the cumulative VIS irradiance (AIC $=42.24$; AIC $=68.83$ in the null model). Thus, the photoreactivation effects were determined by the cumulative VIS irradiance, obeying reciprocity. However, the function of the cumulative VIS irradiance in the photoreactivation efficiency was nonlinear; it increased slowly around the origin, linearly in the next, and then levelled off at higher cumulative irradiances (Fig. 2). This pattern was similar to the logistic curve, but its saturation point did not reach 1 .

Therefore, the following model (3) was fit to the relationship between the cumulative VIS irradiance and the photoreactivation efficiency using a nonlinear least-squares method:

$$
y=\frac{a e^{(b+c x)}}{1+e^{(b+c x)}}
$$


where $y$ and $x$ represent the photoreactivation efficiency and the cumulative VIS irradiance, and $a, b$ and $c$ are constants. The constants were calculated to be 0.57025971 , -3.56120355 and 0.04089434 for $a, b$ and $c$, respectively (Fig. 2; minimum $=$ 0.2635581 ), indicating that up to $57 \%$ of the eggs were reactivated due to photoreactivation from UVB damage.

Consequently, the survival ratio of eggs through photoreactivation (maximum, 0.570 ) and dark repair pathways (or potentially not vitally damaged; 0.106) after UVB irradiation at $0.288 \mathrm{~kJ} \mathrm{~m}^{-2}$ was estimated to be maximum of 0.676 .

Influence of a time lag between UVB and VIS irradiation on photoreactivation in eggs.

Bartlett's test did not reject the homogeneity of variances among the immediate (LAG0) and delayed photoreactivation treatments (LAG1, LAG2, and LAG4) or the dark control (VIS - ) in the $E L$ transforms $(P=0.8958)$. A one-way ANOVA revealed significant differences in egg hatchability among the treatments and control $\left(F_{[4,5]}=\right.$ 66.76, $P=0.000158$ ). The photoreactivation efficiency was reduced as the time lag between UVB and VIS irradiation increased; the percentage of eggs showing reactivation was 62.5\% (57.6-67.3\%) and 2.7\% (2.3-3.2\%) in LAG 0 and LAG4, respectively (Tukey's HSD method, $P<0.05$; Fig. 3). Eventually, no photoreactivation efficacy was detected in LAG4 compared with VIS- (Tukey’s HSD, $P$ > 0.05; Fig. 3).

Influence of a time lag between UVB and VIS irradiation on photoreactivation in larvae.

The homogeneity of variances in the ELs for development to a protochrysalis (day 1) and survival to adulthood (day 8) was supported among the immediate and delayed photoreactivation treatments and dark controls with and without UVB exposure by Bartlett's tests (day $1, P=0.7269$; day $8, P=0.5771$ ). All individuals in all treatments survived on day 1 , and $94.6 \%$ of individuals in the UVB- dark control developed to a protochrysalis (Table 1). In contrast, all individuals remained at the larval stage in the UVB+ dark control (Tukey's HSD, $P<0.05$ ), and they looked healthy. Although no significant differences from the UV- dark control were detected by Tukey's HSD method $(P>0.05)$, exposure to UVB radiation with photoreactivation with or without a 
time lag was likely to delay the development of larvae to protonymphs; up to $70 \%$ of individuals had developed to a protochrysalis on day 1.

In the UVB- dark control, 97.8\% of individuals survived and developed to adulthood, whereas individuals in the UVB+ dark control died by day 8 (Tukey's HSD, $P<0.05$; Table 1). Most individuals in the UVB+ dark control died at the protochrysalis stage or during the moulting period. Up to $96.4-100 \%$ of individuals subjected to photoreactivation with and without a time lag developed (survived) to adulthood, which is not different from that in the UVB- dark control (Tukey's HSD, $P$ > 0.05; Table 1).

Effects of wavelength-filtered VIS and UVA on egg photoreactivation.

The homogeneity of variances in the ELs for hatchability was marginally supported among all treatments, including the dark controls (Bartlett's tests, $P=0.05832$ ). We confirmed the homogeneity of variances in the ELs among all treatments, excluding the dark controls (Bartlett's tests, $P=0.1499$ ). A one-way ANOVA (including the dark controls) showed a significant difference in hatchiability among treatments $\left(F_{[9,10]}=\right.$ 39.03, $P=1.28 \times 10^{-6}$ ). UVA, blue, and, green lights exhibited substantial photoreactivation effects in comparison with the dark control (Tukey's HSD, $P<0.05$; Fig. 4). In contrast, no effects were detected following treatment with yellow and red light, in which the egg hatchability was not significantly different from that in the dark controls (Tukey's HSD, $P$ > 0.05; Fig. 4).

\section{DISCUSSION}

The capacity for substantial photoreactivation by VIS and UVA irradiation was demonstrated in T. urticae eggs and larvae in this study. The T. urticae egg hatchability increased from $10.6 \%$ (dark control) to a maximum of $67.6 \%$ by the sequential VIS irradiation following UVB irradiation. Moreover, the development of UVB-irradiated larvae to adulthood changed drastically from 0 to nearly $100 \%$ following VIS irradiation. Although DNA lesions and repair have not been monitored, our results suggest that photoreactivation is a major biological defense mechanism against DNA damage 
induced by UVB radiation in eggs and larvae of T. urticae. According to Santos (2005), a $20 \%$ increase in adult female $T$. urticae survival was observed following exposure to VIS radiation after UVB irradiation. Therefore, the photoreactivation efficiency was substantially higher at the egg and larval stages, which are vulnerable to UVB damage compared to adult females (Murata and Osakabe 2013).

VIS intensity dependence has been reported in the efficiency of photoreactivation in Smittia sp. (Chironomidae, Diptera; Kalthoff et al. 1978) and Escherichia coli (Kelner 1951). In contrast, reciprocity (cumulative dose dependence) has been reported in the photoreactivation of the Tasmanian rat kangaroo Potorous tridactylus (Kerr) (Chiang and Rupert 1979), and a bacterium (Streptomyces griseus). However, these responses have not been studied sufficiently. For example, in Smittia eggs, the intensity affected photoreactivation more effectively at low VIS intensities, whereas when the period of irradiation is extended to more than $30 \mathrm{~min}$, the length is apparently a determinant of the photoreactivation efficiency (Kalthoff et al. 1978). Such ambiguity might be caused by a shortage of knowledge of how organisms get sick due to UV-induced DNA damage.

The increase in egg hatchability in T. urticae induced by photoreactivation depended on the cumulative VIS irradiance with no regard to intensity, indicating reciprocity. However, the photoreactivation efficiency in T. urticae eggs levelled off. The survival ratio after maximum photoreactivation by the exposure to VIS radiation immediately after UVB irradiation was 0.676 with UVB irradiation of $0.288 \mathrm{~kJ} \mathrm{~m}^{-2}$. This survivorship was lower than the estimated hatchability of 0.877 at $0.288 \mathrm{~kJ} \mathrm{~m}^{-2}$ calculated from the cumulative irradiance-mortality regression line in a study by Murata and Osakabe (2013). In that study, photoreactivation was probably caused during UVB irradiation since the eggs were irradiated with UVB in a laboratory illuminated with fluorescent lamps (Murata and Osakabe 2013).

The photoreactivation efficiency decreased with an increasing time lag between UVB irradiation and VIS irradiation; however, no reactivation effects were observed when the time lag was $4 \mathrm{~h}$ (LAG4). We tentatively determined that eggs aged 24-48 h after oviposition were the most vulnerable to UVB radiation for the egg duration (Fig. S2). As for embryogenesis, $T$. urticae eggs 1 day after oviposition were roughly at the stage in which the larval body is formed based on the germinal disk (Dearden et al., 
2002). Unlike eggs, a 4-h time lag did not affect the efficiency of larval photoreactivation. In larvae, the survivability after UVB irradiation at $0.288 \mathrm{~kJ} \mathrm{~m}^{-2}$ was predicted to be 0.9996 from the linear regression line produced by Murata and Osakabe (2013); this corresponds with the results for photoreactivated larvae in this study.

All larvae exposed to UVB, including with and without photoreactivation, were alive after $24 \mathrm{~h}$ (day 1), although none of the larvae that were not photoreactivated (UVB+ dark control) developed into a protochrysalis. Most individuals in the UVB+ dark control died at the protochrysalis stage or at moulting. The same phenomena were observed in a previous study where larvae exposed to UVB radiation died primarily during the protochrysalis stage or later when failing to moult to protonymphs (Murata and Osakabe, 2013). Moreover, the $\mathrm{LD}_{50}$ value was similar in $T$. urticae teleiochrysalis females (quiescent stage just before adults) to larvae despite a larger body size, and the coefficient of determination $\left(R^{2}\right)$ value and slope of the linear regression line between cumulative UVB irradiance and probit mortality were small (Murata and Osakabe, 2013). The physiological systems for ecdysis are likely to be vulnerable to UVB damage, and vulnerability during the chrysalis stage may vary depending on the phase preceding moulting.

The observed time lag effects in eggs and larvae indicate that mites exposed to UVB radiation sicken at particular developmental phases such as the embryonic phase from germinal disk formation through embryonic development and ecdysis phase of the chrysalis stage. We hypothesize that UVB-induced DNA damage obstruct gene expression at a particular phase of embryogenesis or ecdysis, and mites survive UVB radiation if PER repair the damage before those phases. To demonstrate this hypothesis, detailed molecular analysis is necessary in further studies.

Radiation of 350-450 nm is generally effective for photoreactivation (Rupert 1975; Sancar 2003). PER activity peaks with radiation of 375 and $436 \mathrm{~nm}$ in E. coli and $S$. griseus, respectively (Kelner 1951), 430-450 nm in the cyanobacteria, Agmenllum quadruplicatum (Baalen and O’Donnell 1972), $440 \mathrm{~nm}$ in Smittia sp. (Kalthoff et al. 1978), and $366 \mathrm{~nm}$ in P. tridactylus (Chiang and Rupert 1979). The wavelengths effective for photoreactivation in T. urticae correspond roughly with these general trends; radiation in the range from UVA to green $(\leq 500 \mathrm{~nm})$ was effective. Additional detailed studies are required to elucidate the PER action spectra in spider mites. 
As mentioned above, Tetranychus urticae commonly remain on the lower leaf surface of host plants in the field (Foott 1963; Osakabe et al. 2006). Lower leaf surfaces are protected from solar UVB radiation (Ohtsuka and Osakabe 2009) because plant leaves defend against UV penetration by accumulating substances such as flavonoids (Izaguirre et al. 2007). This may mislead us into thinking that lower leaf surface users such as T. urticae must possess a minimum protective mechanism other than behavioral escape from solar UVB radiation. Indeed, our findings suggest that T. urticae depends on photoreactivation to cope with ambient UVB radiation. Consequently, photoreactivation efficiency is responsible for the divergence in the biological impact of UVB radiation observed between laboratory experiments with a UV lamp (Murata and Osakabe 2013) and outdoor studies with solar radiation (Sakai et al. 2012). Photoreactivation may be essential for $T$. urticae to survive ambient radiation, even though they usually inhabit lower leaf surfaces.

\section{ACKNOWLEDGEMENTS}

We thank participants in Panasonic Co. for providing UVB lamps and for measuring

\section{SUPPORTING INFORMATION}

Additional Supporting Information may be found in the online version of this article:

Fig. S1. Effects of time lag between UVB and VIS radiation on photoreactivation in T. urticae eggs. A figure above each bar represent the number of eggs tested. 
Fig. S2. Egg age and vulnerability to UVB radiation in Tetranychus urticae eggs.

Day 0 represent the egg-age within $24 \mathrm{~h}$ after oviposition. Eggs at each age were once exposed to UVB at $0.19 \mathrm{~W} \mathrm{~m}^{-2}$ for $1 \mathrm{~h}\left(0.684 \mathrm{~kJ} \mathrm{~m}^{-2}\right)$ in a laboratory illuminated with fluorescent lamps at $25^{\circ} \mathrm{C}$. Vertical lines at each plot represent CI. Different letters above plots represent statistical significance between the hatchability (TukeyHSD, $P<$ $0.05)$.

\section{REFERENCES}

Ohtsuka K, Osakabe M (2009) Deleterious effects of UV-B radiation on herbivorous spider mites: they can avoid it by remaining on lower leaf surfaces. Environ Entomol 38:920-929. doi: 10.1603/022.038.0346

Suzuki T, Watanabe M, Takeda M (2009) UV tolerance in the two-spotted spider mite, Tetranychus urticae. J Insect Physiol 55:649-654. doi:

$$
\text { 10.1016/j.jinsphys.2009.04.005 }
$$

Sakai Y, Osakabe M (2010) Spectrum-specific damage and solar ultraviolet radiation avoidance in the two-spotted spider mite. Photochem Photobiol 86:925-932. doi:

$$
\text { 10.1111/j.1751-1097.2010.00739.x }
$$

Murata Y, Osakabe M (2013) The Bunsen-Roscoe reciprocity law in ultraviolet-B-induced mortality of the two-spotted spider mite Tetranychus urticae. J. Insect Physiol 59:241-247. doi: 10.1016/j.jinsphys.2012.11.008

Sakai Y, Sudo M, Osakabe M (2012) Seasonal changes in the deleterious effects of solar ultraviolet-B radiation on eggs of the twospotted spider mite, Tetranychus urticae (Acari: Tetranychidae). Appl Entomol Zool 47:67-73. doi: 10.1007/s13355-011-0090-6

Malloy KD, Holman MA, Mitchell D, Detrich III HW (1997) Solar UVB-induced DNA damage and photoenzymatic DNA repair in Antarctic zooplankton. Proc Natl Acad Sci USA 94:1258-1263.

Sinha RP, Häder DP (2002) UV-induced DNA damage and repair: a review. Photoch Photobio Sci 1:225-236. doi: 10.1039/B201230H

Sancar A (2003) Structure and function of DNA photolyase and cryptochome blue-light photoreceptors. Chem Rev 103:2203-2237. doi: 10.1021/cr0204348 
Kalthoff K (1975) Compensation for solar UV damage by solar radiation of longer wavelengths. Oecologia (Berl.) 18:101-110. doi: 10.1007/BF00348091

Shiroya T, McElroy DE, Sutherland BM (1984) An action spectrum of photoreactivating enzyme from sea urchin eggs. Photochem Photobiol 40:749-751. doi: 10.1111/j.1751-1097.1984.tb04647.x

Santos CD (2005) Photoreactivation of ultraviolet-B damage in Tyrophagus putrescentiae (Acari: Acaridae) and Tetranychus urticae (Acari: Tetranychidae). Internat J Acarol 31:429-431. doi: 10.1080/01647950508683685

Grbić M, Van Leeuwen T, Clark RM, Rombauts S, Rouzé P, Grbić V, Osborne EJ, Dermauw W, Ngoc PCT, Ortego F, Hernández-Crespo P, Diaz I, Martinez M, Navajas M, Sucena É, Magalhães S, Nagy L, Pace RM, Djuranović S, Smagghe G, Iga M, Christiaens O, Veenstra JA, Ewer J, Villalobos RM, Hutter JL, Hudson SD, Velez M, Yi SV, Zeng J, Pires-daSilva A, Roch F, Cazaux M, Navarro M, Zhurov V, Acevedo G, Bjelica A, Fawcett JA, Bonnet E, Martens C, Baele G, Wissler L, Sanchez-Rodriguez A, Tirry L, Blais C, Demeestere K, Henz SR, Gregory TR, Mathieu J, Verdon L, Farinelli L, Schmutz J, Lindquist E, Feyereisen R, Van de Peer Y (2011) The genome of Tetranychus urticae reveals herbivorous pest adaptations. Nature 479:487-492. doi: 10.1038/nature10640

Kelner A (1951) Action spectra for photoreactivation of ultraviolet-irradiated Escherichia coli and Streptomyces griseus. J Gen Physiol 34:835-852. doi: 10.1085/jgp.34.6.835

Ikegami Y, Yano S, Takabayashi J, Takafuji A (2000) Function of quiescence of Tetranychus kanzawai (Acari: Tetranychidae), as a defense mechanism against rain. Appl Entomol Zool 35:339-343. doi: 10.1303/aez.2000.339

Kalthoff K, Urban K, Jäckle H (1978) Photoreactivation of RNA in UV-irradiated insect eggs (Smittia sp., Chironomidae, Diptera). II. Evidence for heterogeneous light-dependent repair activities. Photochem Photobiol 27:317-322. doi:

$$
\text { 10.1111/j.1751-1097.1978.tb07606.x }
$$

Chiang T, Rupert CS (1979) Action spectrum for photoreactivation of ultraviolet irradiated marsupial cells in tissue culture. Photochem Photobiol 30:525-528. doi: 10.1111/j.1751-1097.1979.tb07173.x

Dearden PK, Donly C, Grbić M (2002) Expression of pair-rule gene homologues in a 
485 chelicerate: early patterning of two-spotted spider mite Tetranychus urticae.

486 Development 129:5461-5472. doi: 10.1242/dev.00099

487 Rupert CS (1975) Enzymatic photoreactivation: overview. In: Hanawalt PC, Setlow RB 488 (ed) Molecular Mechanisms for Repair of DNA, Part A. Plenum Press, New York, pp $489 \quad 73-87$.

490 Baalen CV, O’Donnell R (1972) Action spectra for ultraviolet killing and

491 photoreactivation in the blue-green alga Agmenellum quadruplicatum. Photochem

492 Photobiol 15:269-274. doi: 10.1111/j.1751-1097.1972.tb07331.x

493 Foott WH (1963) Competition between two species of mites. II. Factors influencing 494 intensity. Can Entomol 95:45-57. doi: 10.4039/Ent9545-1

495 Osakabe M, Hongo K, Funayama K, Osumi S (2006) Amensalism via webs causes

496 unidirectional shifts of dominance in spider mite communities. Oecologia 150:496-

497 505. doi: $10.1007 / \mathrm{s} 00442-006-0560-7$

498 Izaguirre MM, Mazza CA, Svatoš A, Baldwin IT, Ballaré CL (2007) Solar ultraviolet-B

499 radiation and insect herbivory trigger partially overlapping phenolic responses in

$500 \quad$ Nicotiana attenuata and Nicotiana logiflora. Ann Bot 99:103-109. doi:

$501 \quad 10.1093 /$ aob/mcl226 


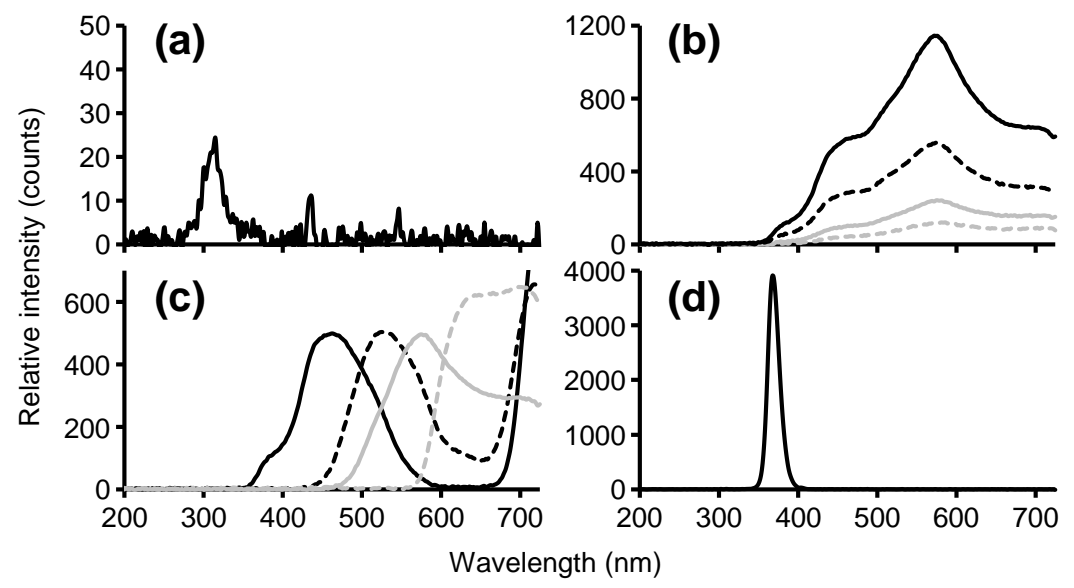

Fig 1. Wavelength spectra of UVB, UVA, and VIS. (a) UVB lamp. (b) Halogen lamp (grey dashed line, 21.6 $\mathrm{W} \mathrm{m}^{-2}$; grey line, $36.8 \mathrm{~W} \mathrm{~m}^{-2}$; dashed line, $67.7 \mathrm{~W} \mathrm{~m}^{-2}$; solid line, $142 \mathrm{~W} \mathrm{~m}^{-2}$ ). (c) Coloured VIS (solid line, blue; dashed line, green; grey line, yellow; grey dashed line, red). (d) UVA lamp. 


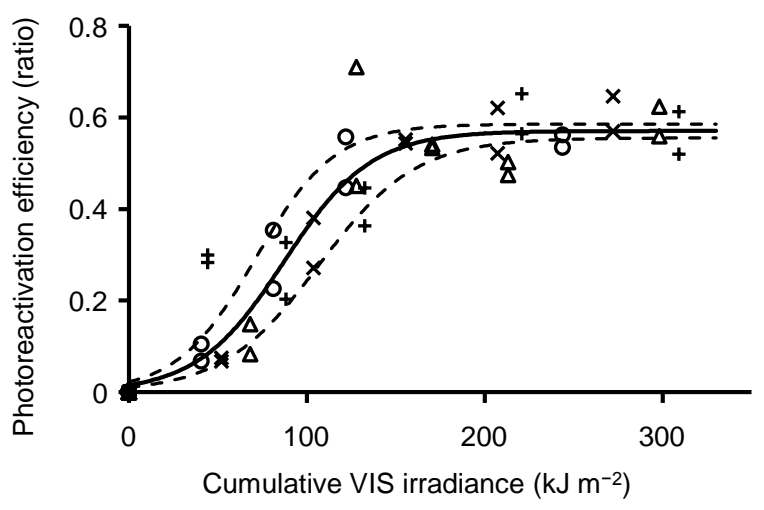

Fig 2. Effects of cumulative VIS irradiance on egg photoreactivation. The solid line is the regression curve fitted by a nonlinear least-squares method using formula (3). Dashed lines represent the 95\% CI range.

Fig. 2 


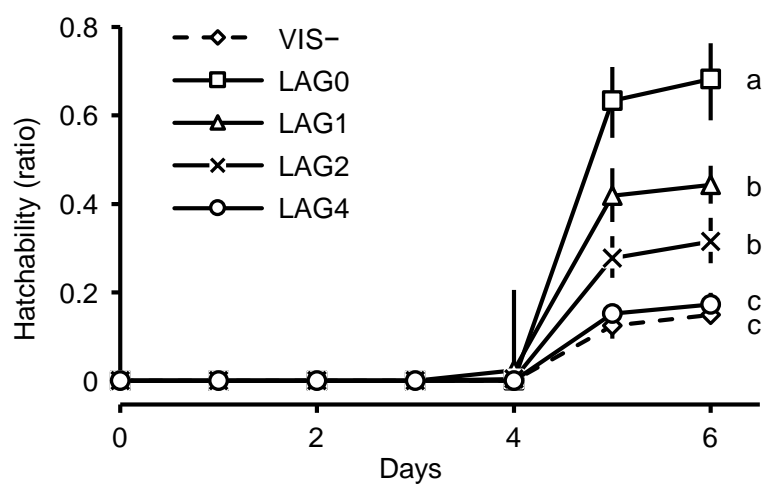

Fig 3. Effects of a time lag between UVB and VIS irradiation on egg photoreactivation. Different letters represent significance (Tukey’s HSD, P < 0.05). VIS-, dark control; LAG0, without a time lag; LAG1, 1-h time lag; LAG2, 2-h time lag; and LAG4, 4-h time lag. The vertical lines in each plot represent the 95\% CI range.

Fig. 3 


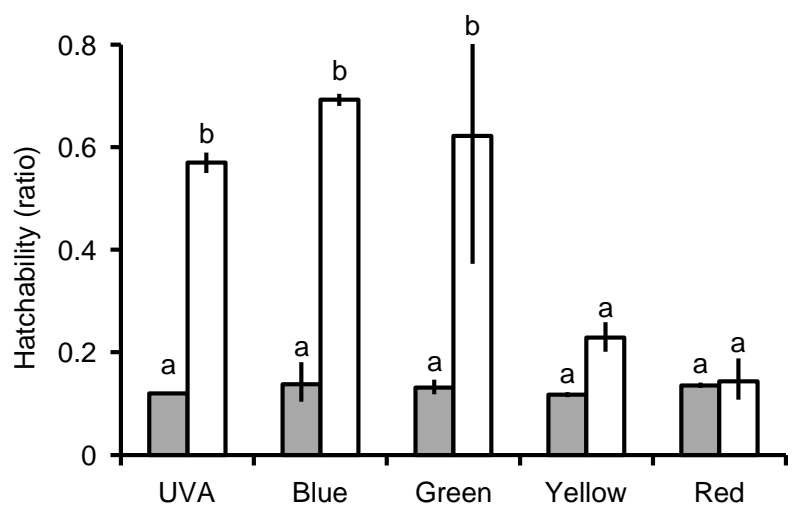

Fig 4. Effects of coloured VIS and UVA on egg photoreactivation. White bars represent the hatchability of eggs exposed to VIS and UVA after exposure to UVB radiation. Grey bars represent the hatchability of eggs exposed to UVB without photoreactivation (dark control). The vertical line at the top of each bar shows the 95\% CI range. Different lowercase letters indicate significant differences in hatchability (Tukey's HSD, $P<0.05$ ).

Fig. 4 


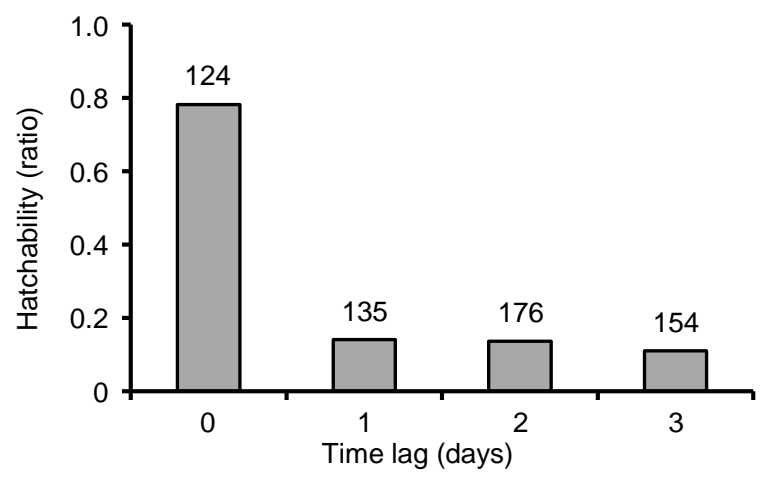

Fig. S1 Effects of time lag between UVB and VIS radiation on photoreactivation in $T$. urticae eggs. A figure above each bar represent the number of eggs tested.

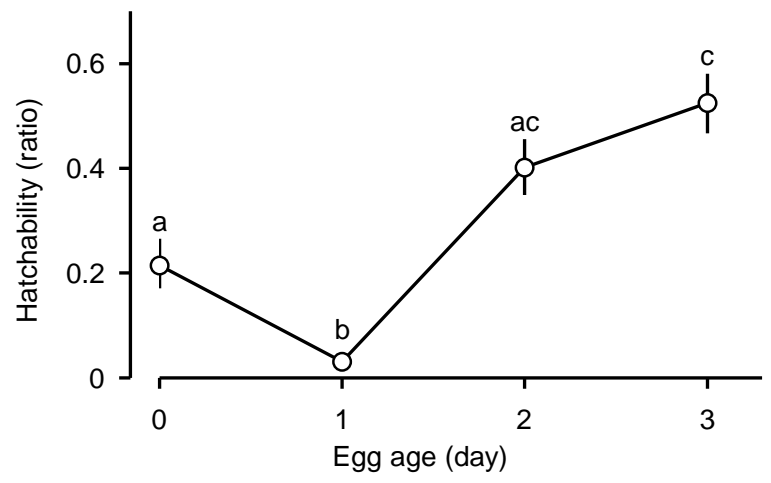

Fig. S2 Egg age and vulnerability to UVB radiation in Tetranychus urticae eggs. Day 0 represent the egg-age within $24 \mathrm{~h}$ after oviposition. Eggs at each age were once exposed to UVB at $0.19 \mathrm{~W}$ $\mathrm{m}^{-2}$ for $1 \mathrm{~h}\left(0.684 \mathrm{~kJ} \mathrm{~m}^{-2}\right)$ in a laboratory illuminated with fluorescent lamps at $25^{\circ} \mathrm{C}$. Vertical lines at each plot represent $\mathrm{Cl}$. Different letters above plots represent statistical significance between the hatchability (TukeyHSD, $P<0.05$ ). 